\title{
Impact of optimized pest control schemes on mandarin yield in the Republic of Abkhazia
}

\author{
Natalia Karpun ${ }^{1, *}$, Levan Kulava ${ }^{1,2}$, Elena Zhuravleva ${ }^{1}$, and Elena Shoshina ${ }^{1}$ \\ ${ }^{1}$ Federal Research Centre the Subtropical Scientific Centre of the Russian Academy of Sciences, 2/28 \\ Yana Fabritsiusa Street, Sochi, 354002, Russia \\ ${ }^{2}$ Institute of agriculture of Academy of sciences of Abkhazia, 22 Gulia Street, Sukhum 384900, \\ Republic of Abkhazia
}

\begin{abstract}
Pests of mandarin reduce significantly crop productivity and commercial quality of the crop in Abkhazia. We assessed the impact of optimized mandarin pest control schemes on fruit size and crop yield in the humid subtropics of Abkhazia. The studies were carried out in 2019-2020 on full-aged plantings of cv. Unshiu mandarin in Gulrypsh district of Republic of Abkhazia on the base of Institute of agriculture of Academy of sciences of Abkhazia. The highest yield and quality of fruits was shown by the protection schemes in variants 5 (Confidor extra $(0.05 \%)+$ Cytovit $(0.15 \%)$ - the 1 st treatment Vertimec $(0.1 \%)+$ Cytovit $(0.15 \%)$ - the second treatment; the third and fourth treatments Karate Zeon $(0.05 \%)+$ Cytovit $(0.15 \%))$ and 6 (Metomax $(0.15 \%)+\operatorname{Vertimec}(0.1 \%)-$ the 1 st treatment; Karate Zeon $(0.05 \%)+$ Vertimec $(0.1 \%)$ in the other three treatments). The average fruits weight in these variants was up to $72-74 \mathrm{~g}$. This exceeded the fruits weight in the Standard variant by $22.0-25.4 \%$. The yield was $46.2-44.7 \mathrm{t} / \mathrm{ha}$, which is $36.8-41.3 \%$ higher than the standard variant. Fruits of the 1st grade in the named variants accounted for $63.3-65.6 \%$ of the total yield.
\end{abstract}

\section{Introduction}

In the modern period, citrus crops occupy a leading place in the agriculture of the Republic of Abkhazia, among which mandarin (Citrus reticulata subsp. unshiu (Marcow.) D. Rivera $\&$ al.) is the main industrial crop. Mandarin agrocenoses account for more than $90 \%$ of the area occupied by citrus crops [1].

It is known that pests can significantly reduce the yield and quality of fruits, as well as lead to a complete loss of yield and even to the death of plants [2]. The degree of distribution and development of pests affects the quantitative and qualitative characteristics of the productivity of agricultural crops. So, crop yield loss from pests amounted to 601 million tons in 2000-2015 [3]. The cultivation of mandarin in the conditions of Abkhazia, as in other regions of the world, faces difficulties in the field of plant protection from pests $[1,4-6]$. More than 50 pest species have been recorded on citrus crops in the Black Sea region of the Caucasus. These species differ in the degree of their influence on the state of

* Corresponding author: nkolem@mail.ru 
citrus crops, the size and quality of the harvest [6-8]. The appearance in the region of the brown marmorated stink bug (Halyomorpha halys Stål.) reduced the yield of standard mandarin fruits and led to a $40 \%$ decrease in the export of culture from Abkhazia to Russia in 2017 [9].

In technologies of mandarin protection from pests in the conditions of Abkhazia, organophosphate pesticides, mineral oil emulsions and lime-sulfur broth are traditionally used to this day. Farmers use modern insecticides, as a rule, without a scientific approach. This leads to an increase in the resistance of pests to the used active substances, oppression of plants, a decrease in yield, the accumulation of residual amounts of pesticides in agrocenoses. Optimization of mandarin protection schemes using modern insecticides and insectoacaricides from the classes of avermectins, pyrethroids and neonicotinoids is a very urgent task. An important issue in fruit (including subtropical) crops cultivation technologies is the influence of certain technology elements on the quality of fruits (their size and weight), as well as on productivity as an integrated indicator [3]. So, plant protection as an element of agricultural crops cultivation technology, contributes not only to the preservation of yield, but can lead to its increase and improve the fruits quality $[10,11]$.

The aim of the research was to study the effect of the use of new mandarin protection schemes from pests on fruits weight and crop yield in the humid subtropics of Abkhazia.

\section{Materials and methods}

The studies were carried out in 2019-2020 on full-aged plantings of cv. Unshiu mandarin in Gulrypsh district of Republic of Abkhazia on the base of Institute of agriculture of Academy of sciences of Abkhazia.

The experiments were laid down according to generally accepted methods $[12,13]$. The scheme of experience included 8 variation. In each case, 4 treatments were carried out: in the second decade of June, in the second decade of July, in the second decade of August and in the second decade of September.

1 st variation. Control. Without insecticide treatment. Water treatment.

2nd variation - Standard. All four treatments with the Bi-58 tank mixture (dimethoate, $400 \mathrm{~g} / \mathrm{l})(0.2 \%)+$ Drug 30 Plus (vaseline oil, $760 \mathrm{~g} / \mathrm{kg})(3 \%)$.

$3 \mathrm{rd}$ variation. The first treatment - Confidor extra (imidacloprid, $700 \mathrm{~g} / \mathrm{kg})(0.05 \%)$; the second treatment - Vertimec (abamectin, $18 \mathrm{~g} / \mathrm{l})(0.1 \%)$; the third and fourth treatments - Karate Zeon (lambda-cyhalothrin, $50 \mathrm{~g} / \mathrm{l})(0.05 \%)$.

4 th variation. The first treatment is a tank mixture of Confidor extra (imidacloprid, 700 $\mathrm{g} / \mathrm{kg})(0.05 \%)$ and Siliplant $(0.15 \%)$; the second treatment is a tank mixture of Vertimec (abamectin, $18 \mathrm{~g} / 1)(0.1 \%)$ and Siliplant $(0.15 \%)$; the third and fourth treatments are a tank mixture of Karate Zeon (lambda-cyhalothrin, $50 \mathrm{~g} / 1)(0.05 \%)$ and Siliplant $(0.15 \%)$.

5 th variation. The first treatment is a tank mixture of Confidor extra (imidacloprid, 700 $\mathrm{g} / \mathrm{kg})(0.05 \%)$ and Cytovit $(0.15 \%)$; the second treatment is a tank mixture of Vertimec (abamectin, $18 \mathrm{~g} / \mathrm{l})(0.1 \%)$ and Cytovit $(0.15 \%)$; the third and fourth treatments are a tank mixture of Karate Zeon (lambda-cyhalothrin, $50 \mathrm{~g} / \mathrm{l})(0.05 \%)$ and Cytovit $(0.15 \%)$.

6 th variation. The first treatment is a tank mixture of Metomax (Metomil $250 \mathrm{~g} / \mathrm{kg}+$ bifentrin $25 \mathrm{~g} / \mathrm{kg})(0.15 \%)$ and Vertimec (abamectin, $18 \mathrm{~g} / \mathrm{l})(0.1 \%)$; the second, third and fourth treatments are Karate Zeon (lambda-cyhalothrin, $50 \mathrm{~g} / \mathrm{l})(0.05 \%)$ and Vertimec (abamectin, $18 \mathrm{~g} / \mathrm{l})(0.1 \%)$.

7 th variation. All four treatments with Diatomite (diatomite flour, silicon oxide $75 \%$ ) (3\%).

8th variation. All four treatments with Diatomite (diatomite flour, silicon oxide $75 \%$ ) $(6 \%)$. 
Siliplant is a universal fertilizer with a high content of bioactive silicon ( $\mathrm{Si}-7 \%$ ), potassium $(\mathrm{K}-1 \%)$ and trace elements in chelated form (mg/l): $\mathrm{Fe}-300 ; \mathrm{Mg}-100 ; \mathrm{Cu}-$ 70-240; $\mathrm{Zn}-80 ; \mathrm{Mn}-150$; Co - 15; B - 90 .

Cytovit is a fertilizer containing macronutrients $(\mathrm{g} / \mathrm{l})$ : nitrogen -30 ; phosphorus -5 ; potassium - 25; and trace elements in chelated form $(\mathrm{g} / \mathrm{l})$ : magnesium -10 , sulfur -40 , iron -35 , manganese -30 , boron -8 , zinc -6 , copper -6 , molybdenum -4 , cobalt -2 .

Diatomite is a fine diatomite flour. Composition: $\mathrm{SiO}_{2}-74,8-88,0 \%, \mathrm{Al}_{2} \mathrm{O}_{3}-3,3-9,7$ $\%, \mathrm{CaO}-0,6 \%, \mathrm{~K}_{2} \mathrm{O}-0,96 \%, \mathrm{Fe}_{2} \mathrm{O}_{3}-2,3-4,8 \%, \mathrm{MgO}-0,6-1,7 \%, \mathrm{Na}_{2} \mathrm{O}-0,74 \%$.

The fruits on the experimental plots was harvested in one day. Mandarin yield was determined by the gravimetric method (Scout Pro SPS202F scales) during the harvesting period according to the methodology for state agricultural crops variety testing [13].

Statistical processing of the research results was carried out according to Dospekhov [14] using the mathematical software package MS Excel 2010.

\section{Results and discussion}

Analysis of the obtained data showed that optimized plant protection schemes affect the weight of mandarin fruits. The smallest indicators of fetal weight were in the control variant $-38 \mathrm{~g}$ (Table 1).

Table 1. Yield of cv. Unshiu mandarin in variants with different protection schemes (Abkhazia, Gulrypsh district, 2019-2020).

\begin{tabular}{|c|c|c|c|}
\hline $\begin{array}{c}\text { Variant of protection } \\
\text { schemes }\end{array}$ & $\begin{array}{c}\text { Middle } \\
\text { fetal weight, } \mathrm{g}\end{array}$ & $\begin{array}{c}\text { Harvest, } \\
\mathrm{kg} / \mathrm{plant}\end{array}$ & $\begin{array}{c}\text { Yield, } \\
\mathrm{t} / \mathrm{ha}\end{array}$ \\
\hline Control & $38.0 \pm 1.2$ & 48.2 & 24.1 \\
\hline Standard & $59.0 \pm 2.1$ & 65.4 & 32.7 \\
\hline Variant 3 & $69.0 \pm 2.8$ & 81.3 & 40.6 \\
\hline Variant 4 & $68.0 \pm 2.8$ & 78.3 & 39.1 \\
\hline Variant 5 & $72.0 \pm 3.2$ & 89.5 & 44.7 \\
\hline Variant 6 & $74.0 \pm 3.2$ & 92.4 & 46.2 \\
\hline Variant 7 & $43.0 \pm 1.4$ & 59.6 & 29.8 \\
\hline Variant 8 & $46.0 \pm 1.7$ & 61.8 & 30.9 \\
\hline$L S D_{0,05}$ & 6.4 & 7.6 & 3.8 \\
\hline
\end{tabular}

The application of the plant protection scheme adopted in the region (standard) increased the average fruit weight by $55.2 \%$. The greatest increase in the weight of mandarin fruits was noted when applying the protection scheme according to 5 th and 6 th variations. The average fetal weight increased by 89.5 and $94.7 \%$ relative to the control variant, respectively, and by 22.0 and $25.4 \%$ relative to the variant of adopted in region treatment (Standard). In the variants with the use of Diatomite, the lowest values of fruits fetal weight were noted, which may be due to the insufficient effectiveness of these variants in relation to mandarin pests. The weight of the fruits was lower than the Standard option, and in the case of using Diatomite $3 \%$, it even slightly differed from the option without treatment (control). 
The number of fruits per tree varied on average from 1108 to 1386 . The yield per tree and the yield per hectare were determined by calculation. Thus, the highest yield values were obtained in variants five and six. The excess of the yield values in these variants was, 85.7 and $91.7 \%$ relative to the control variant, respectively, and 36.8 and $41.3 \%$ relative to the Standard variant (Figure 1).
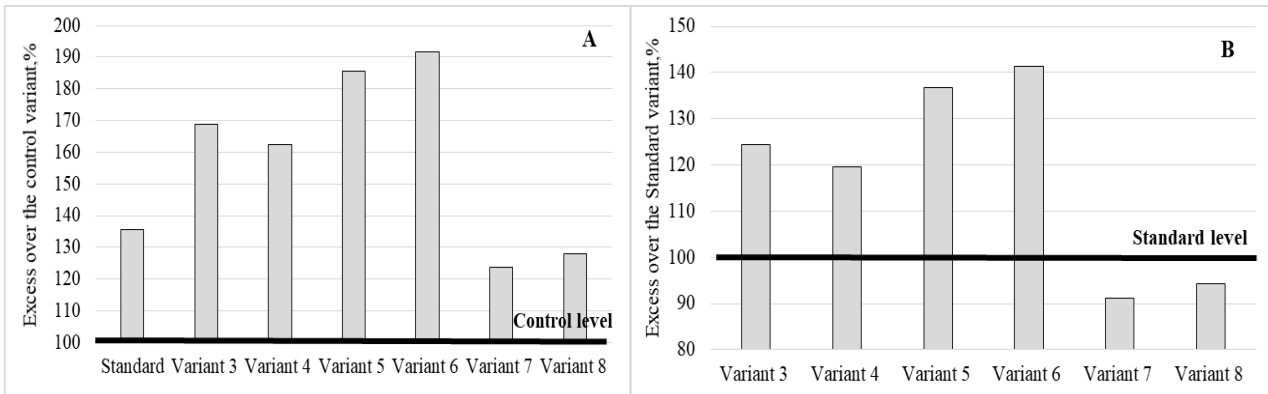

Fig. 1. Excess of cv. Unshiu mandarin yield in variants with different protection schemes over control (A) and over the standard (B) (Abkhazia, Gulrypsh district, 2019-2020).

In addition to the total yield, an important aspect is the marketability (commodity structure) of the harvested crop. Marketability comes first in the production of fruit and berry crops [15]. So, in the control variant, fruits of the 1st grade were not harvested (Table 2). The collected fruits were small, damaged by a citrus rust mite (Phyllocoptruta oleivora Ashmead) and a brown marmorated stink bug (Halyomorpha halys Stål.). The share of nonstandard fruits was maximal (74,3\%).

Table 2. Commodity structure of cv. Unshiu mandarin yield in variants with different protection schemes (Abkhazia, Gulrypsh district, 2019-2020).

\begin{tabular}{|c|c|c|c|c|}
\hline \multirow{2}{*}{ Variant of protection schemes } & \multirow{4}{|c|}{ Harvest, kg / plant } \\
\cline { 2 - 5 } & \multirow{2}{*}{ total } & including \\
\cline { 3 - 5 } & & 1 st grade & 2nd grade & non-standard \\
\hline Control & 48.2 & 0 & 12.4 & 35.8 \\
\hline Standard & 65.4 & 30.7 & 21.2 & 13.5 \\
\hline Variant 3 & 81.3 & 46.4 & 19.9 & 15 \\
\hline Variant 4 & 78.3 & 44.6 & 19.8 & 13.9 \\
\hline Variant 5 & 89.5 & 63.3 & 20.3 & 5.9 \\
\hline Variant 6 & 92.4 & 65.6 & 19.7 & 7.1 \\
\hline Variant 7 & 59.6 & 5.9 & 23.8 & 29.9 \\
\hline Variant 8 & 61.8 & 6.7 & 26.2 & 28.9 \\
\hline
\end{tabular}

The commodity structure of the crop in different variants can be clearly seen in Figure 2. The maximum number of fruits of the 1 st grade was harvested in variants 5 and 6 , slightly less in variants 3 and 4 . The last two options show the commodity structure of the crop, similar to Standard variant. 


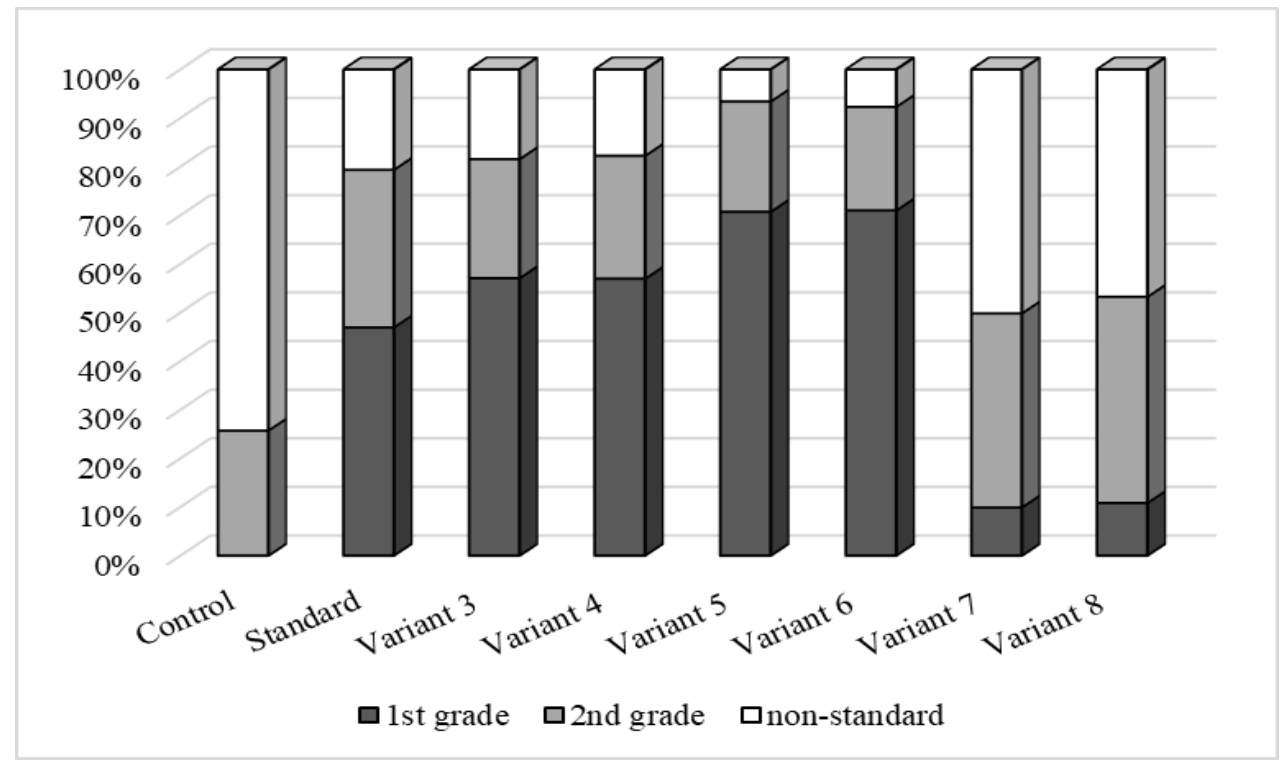

Fig. 2. Commodity structure of cv. Unshiu mandarin yield in variants with different protection schemes (Abkhazia, Gulrypsh district, 2019-2020.

Diatomite protection schemes could not reliably protect the fruit from damage by the citrus rust mite and the brown marmorated stink bug, so about half of the fruit turned out to be non-standard. In addition, a white bloom of the drug remained on the fruits during the harvest period, which had to be washed off before selling.

\section{Conclusion}

Thus, the highest economic efficiency was shown by mandarin protection schemes with alternation of Confidor extra, Vertimec and Karate Zeon in a tank mixture with Cytovit fertilizer, as well as with alternating Metomax and Karate Zeon in a tank mixture with Vertimec insectoacaricide. They increased the average fruit weight by $22.0-25.4 \%$ and the yield by $36.8-41.3 \%$ relative to the standard variant. Fruits of the 1 st grade accounted for $63.3-65.6 \%$ of the total harvest.

\section{Acknowledgements}

The publication was prepared as part of the implementation of the state task of the Federal Research Centre the Subtropical Scientific Centre of the Russian Academy of Sciences No 0492-2021-0007.

\section{References}

1. D. Sabekia, Economic and biological assessment of mandarin in the Republic of Abkhazia (Sochi, 2016)

2. O. M. Kasynkina, I. P. Koshelyaeva, Niva Volga region [Niva Povolzh'ya], 4(41), 21 24 (2016)

3. S.S. Sanin, Plant protection and quarantine 2, 3-10 (2019) 
4. F. Karamaouna, P. Mylonas, D. Papachristos, D. Kontodimas, A. Michaelakis, E. Kapaxidi, Integrated Management of Plant Pests and Diseases 5, 29-59 (2010). doi: 10.1007/978-90-481-8606-8_2

5. G. Lo Verde, V. Caleca, V. Lo Verde, Bulletin of Insectology 64(1), 127-134 (2011)

6. L.D. Kulava, N.N. Karpun, Subtropical and ornamental horticulture 61, 189-196 (2017)

7. M. Batsankalashvili, M.B. Kaydan, G. Kirkitadze, G. Japoshvili, Annals of Agrarian Science 15, 252-268 (2017). doi: 10.1016/j.aasci.2017.05.002

8. N. N. Karpun, The structure of woody plants pests complexes in the humid subtropics of Russia and the biological substantiation of protection measures (Sochi, 2018)

9. S. N. Raldugina, R. V. Kulyan, Subtropical and ornamental horticulture 64, 19-25 (2018)

10. S.S. Sanin, B.I. Sandukhadze, R.Z. Mamedov, L.V. Karlova, L.G. Korneva, O.M. Ruleva, Agrochemistry 10, 36-44 (2020)

11. L.N. Khomitskaya, Plant protection and quarantine 6, 6-7 (2020)

12. V.I. Dolzhenko, Guidelines for registration testing of insecticides, acaricides, molluscicides and rodenticides in agriculture (St-Petersburg, 2009)

13. M.A. Fedin, Methodology for state agricultural crops variety testing (Moscow, 1985)

14. B. A. Dospekhov, Methodology of field experience (Moscow, Alliance, 2011)

15. N. Yu. Petrov, Yu. A. Bulanova, Bulletin of the Nizhnevolzhsky agro-university complex: Science and higher professional education 3(31), 67-69 (2013) 